\title{
COMPARATIVE ASSESSMENT OF NUTRITIONAL STATUS IN URBAN SCHOOL CHILDREN USING THREE DIFFERENT GROWTH SCALES
}

\author{
Subhash Poyekar1, Deepali Ambike², Swati Raje3, Oshmi Rao ${ }^{4}$
}

${ }^{1}$ Assistant Professor, Department of Paediatrics, MIMER Medical College, Talegaon Dabhade, Pune, Maharashtra.

2 Professor and HOD, Department of Paediatrics, MIMER Medical College, Talegaon Dabhade, Pune, Maharashtra.

${ }^{3}$ Assistant Professor \& Statistician, Department of Community Medicine, MIMER Medical College, Talegaon Dabhade, Pune,

Maharashtra.

${ }^{4} 3^{\text {rd }}$ Year MBBS Student, MIMER Medical College, Talegaon Dabhade, Pune, Maharashtra.

\begin{tabular}{l} 
ABSTRACT \\
\hline BACKGROUND
\end{tabular}

\section{BACKGROUND}

School age and adolescence represent a dynamic period of physical growth as well as of mental development. Children are particularly vulnerable to nutritional disorders during these periods. Nutritional status of children in these age groups are assessed and monitored commonly by using weight and height for age/gender growth charts. Though BMI (Body Mass Index) is widely used in adult population to define overweight/obesity, it is not used in children routinely to assess nutritional status, especially overnutrition.

Aims and Objectives-

1. To estimate the prevalence of underweight, overweight and obesity in school children using Revised Indian Academy of Paediatrics 2015 growth charts.

2. To compare the difference in rate of prevalence of unhealthy nutritional status by using weight for age/gender and BMI for age/gender criteria.

\section{MATERIALS AND METHODS}

A cross-sectional/observational study was conducted in Urban Schools. Student's anthropometric data was recorded from classes II (Age- 7 years), V (Age- 10 years) and VIII (Age- 13 years). A Revised Indian Academy of Paediatrics 2015 growth charts were used to assess the nutritional status.

\section{RESULTS}

Out of 1154 children, 698 (60.4\%) were boys and 456 (39.6\%) were girls. The prevalence of overweight was $10.83 \%$ (10.88\% boys and $10.74 \%$ girls) and that of obesity was $5.11 \%$ (4.30\% boys and $6.36 \%$ girls). At the same time, $9.73 \%$ children were underweight using BMI for age/gender as criteria. Obesity was more in adolescent girls. The proportion of overweight and obesity increased with age in girls. The number of children identified as underweight, overweight/obese was more when BMI for age/gender was used as criteria.

\section{CONCLUSION}

Amongst the various anthropometric parameters used to assess nutritional status in children and adolescents, BMI for age/gender is a better indicator for early recognition of undernutrition as well as overnutrition during mid-childhood and adolescence period. By monitoring BMI in all children, Healthcare professionals can play a significant role in preventing undernutrition as well as overweight and obesity amongst school children.

\section{KEYWORDS}

Children, Body Mass Index, Overweight, Obesity, Prevalence.

HOW TO CITE THIS ARTICLE: Poyekar S, Ambike D, Raje S, et al. Comparative assessment of nutritional status in urban school children using three different growth scales. J. Evolution Med. Dent. Sci. 2017;6(49):3785-3788, DOI: 10.14260/Jemds/2017/818
BACKGROUND
The children in developing countries including India presently suffer from the double threat of overnutrition and undernutrition due to a rapid epidemiological, nutritional and demographic transitions.(1.2) Due to targeted interventions to address the problem of undernutrition, the prevalence of undernutrition is on decline, but at the same
Financial or Other, Competing Interest: None.
Submission 20-06-2017, Peer Review 08-06-2017,
Acceptance 13-06-2017, Published 19-06-2017.
Corresponding Author:
Dr. Deepali Ambike,
Department of Paediatrics,
MIMER Medical College,
Talegaon Dabhade, Pune, Maharashtra.
E-mail: ambikedeepa@gmail.com
DOI: $10.14260 /$ jemds $/ 2017 / 818$
time the combined prevalence of overweight and obesity in school children have increased at alarming rate. This is largely due to rapid urbanisation leading to increased energy intake in the form of high-calorie snack and junk food along with reduced energy expenditure.
School age and adolescence are the phases of rapid growth.(3) It represents a dynamic period of physical growth as well as of mental development of the child. Children are particularly vulnerable to nutritional disorders.
There are various anthropometric methods for assessing nutritional status: For instance, weight, height, Body Mass Index (BMI), skinfolds, Mid-Upper Arm Circumference (MUAC) and bioimpedance assessment. Weight for age charts is still widely used due to ease measurements. But it does not distinguish between current Malnutrition and previous Malnutrition.(4) Even this parameter provides restricted information on body composition. 
Though weight/height ratio corresponds to the relationship between real weight and ideal weight, it does not indicate the difference between lean body mass and fat mass. ${ }^{(5)}$ Body Mass Index (BMI) is obtained by dividing weight (in kilograms) by squared height (in metres).(6) It has good correlation with body fat, especially internal fat.(7) Though it is widely used in adult population to define obesity, it is not routinely used in children. By monitoring BMI of school children, especially adolescent can provide an opportunity to identify obesity amongst them and to take appropriate measure for preventing the consequences thereof.(7)

The present analysis describes the prevalence of underweight, overweight and obesity in school children and utility of using BMI as a parameter for early identification of unhealthy nutritional status in school children from urban area of Pune.

\section{Aims and Objectives}

With the above background, a study was undertaken with the following aims and objectives-

1. To estimate the prevalence of underweight, overweight and obesity in school children using Revised Indian Academy of Paediatrics 2015 growth charts. (8)

2. To compare the difference in prevalence of underweight, overweight and obesity by using Weight for age/gender and BMI for age/gender criteria.

\section{MATERIALS AND METHODS}

Institutional Ethical Committee Approval was taken for the study. A cross-sectional study was conducted on students studying in classes II (Age- 7 years), V (Age- 10 years) and VIII (Age- 13 years) in an urban school of Pune using purposive sampling method; 1154 students present at the time of annual health checkup were included in the sample after obtaining consent from School Authorities. Student's identity is kept confidential. The students were explained about the study procedure before beginning measurements. Standard equipment and methodology were used to take Anthropometric measurements. Weight was recorded using digital weighing scale to nearest 100 grams without shoes and with light clothes. Height was recorded using the stadiometer attached to the wall to the nearest $0.1 \mathrm{~cm}$. Body mass index was calculated as the ratio of body weight in $\mathrm{kg} /$ height in meter squared expressed as $\mathrm{kg} / \mathrm{m}^{2}$.

\section{Criteria used to define the Nutritional Status}

- A Revised Indian Academy of Paediatrics 2015 growth charts. ${ }^{(8)}$

- Weight for age criteria: < 3\%= Underweight, > 90\%= Overweight, $>97 \%=$ obese.

- Children with BMI < 5\% were categorised as Underweight/Thin and those with BMI of 23 Adult equivalent were termed as Risk of Overweight and those with BMI of 25 Adult equivalent were termed as Risk of Obesity.

- Data were entered in MS Excel and analysed using SPSS 19. Standard normal/"Z" test was used to determine associations. $\mathrm{P}<0.05$ were considered statistically significant.

\section{RESULTS}

Out of 1154 children of age groups of 7 years, 10 years and 13 years, $698(60.4 \%)$ were boys and 456 (39.6\%) were girls. Distribution of children according to their nutritional status is shown in Figure 1. It was observed that 59 children (5.11\%) were obese, 125 (10.83\%) were overweight and 110 (9.53\%) were underweight.

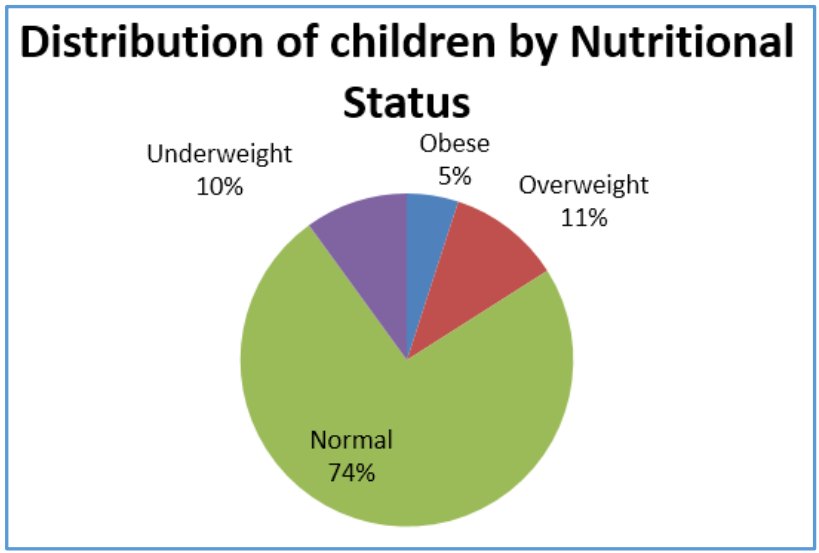

\section{Figure 1}

Table 1. Below gives the average BMI of the study population according to their gender and age group.

\begin{tabular}{|c|c|c|c|}
\hline Standard Group & Sex & No & BMI Mean \pm SD \\
\hline \multirow[t]{2}{*}{ II (7 years) } & Male & 229 & $14.45 \pm 2.08$ \\
\hline & Female & 158 & $13.79 \pm 1.74$ \\
\hline \multirow[t]{2}{*}{$\mathrm{V}$ (10 years) } & Male & 206 & $15.57 \pm 2.79$ \\
\hline & Female & 152 & $16.31 \pm 3.28$ \\
\hline \multirow[t]{2}{*}{ VIII (13 years) } & Male & 263 & $17.12 \pm 3.39$ \\
\hline & Female & 146 & $22.58 \pm 4.06$ \\
\hline Total & & 1154 & \\
\hline
\end{tabular}

It was observed that Girls in age group of 7 years had a lower BMI as compared to boys; however, in higher age groups their BMI surpassed that of boys.

A combined prevalence of overweight and obesity was compared with using weight for age criteria and BMI for age/gender and is depicted in Table 2 .

\begin{tabular}{|c|c|c|c|c|c|c|}
\hline & \multicolumn{3}{|c|}{ Boys } & \multicolumn{3}{c|}{ Girls } \\
\hline & $\begin{array}{c}7 \\
\text { yrs. } \\
(229)\end{array}$ & $\begin{array}{c}10 \\
\text { yrs. } \\
(207)\end{array}$ & $\begin{array}{c}13 \\
\text { yrs. } \\
(264)\end{array}$ & $\begin{array}{c}7 \\
\text { yrs. } \\
(158)\end{array}$ & $\begin{array}{c}10 \\
\text { yrs. } \\
(152)\end{array}$ & $\begin{array}{c}13 \text { yrs. } \\
(146)\end{array}$ \\
\hline $\begin{array}{c}\text { Weight } \\
\text { for Age }\end{array}$ & 16 & 13 & 18 & 8 & 19 & 20 \\
\hline BMI & 38 & 38 & 40 & 12 & 31 & 35 \\
\hline Z & 3.22 & 3.807 & 3.08 & 0.925 & 1.866 & 2.26 \\
\hline P & $<0.001$ & $<0.001$ & $<0.001$ & $>0.05$ & $>0.05$ & $<0.05$ \\
\hline \multicolumn{7}{|c|}{ Table 2. Difference in Combined Prevalence of } \\
Overweight and Obesity as Indicated by Weight \\
for Age and by BMI as Criteria
\end{tabular}

It has been observed that the number of children identified as overweight and obese was more when BMI for age/gender was used as a criterion. The differences were highly significant in all the age groups in boys $(\mathrm{Z}=3.22$, = 3.807 , = 3.08 for age groups 7 yrs., 10 yrs. and 13 yrs. respectively). In adolescent girls, i.e. age group of 13 years the difference was statistically significant $(\mathrm{Z}=2.26, \mathrm{p}<0.05)$. 
The prevalence of underweight was separately studied among boys and girls by age groups and using Weight for age v/s BMI as parameters to define it as shown in Figure 2.

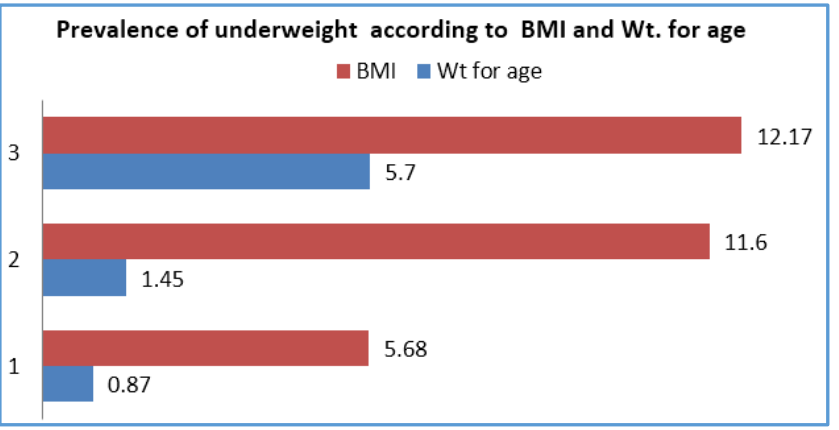

\section{Figure 2}

1. Age group- 7 years; 2 . Age group- 10 years; 3 . Age group13 years

It has been observed that even the proportion of children with undernutrition was more using BMI for age/gender as criteria.

Further analysis of the study population as regards to the combined prevalence of overweight and obesity has shown the increase in the proportion from age 7 years to 10 years and decline in age group of 13 years (Adolescent) as far as boys were concerned. However, in girls the proportions have increased as age advanced. It is shown in Figure 3 below.

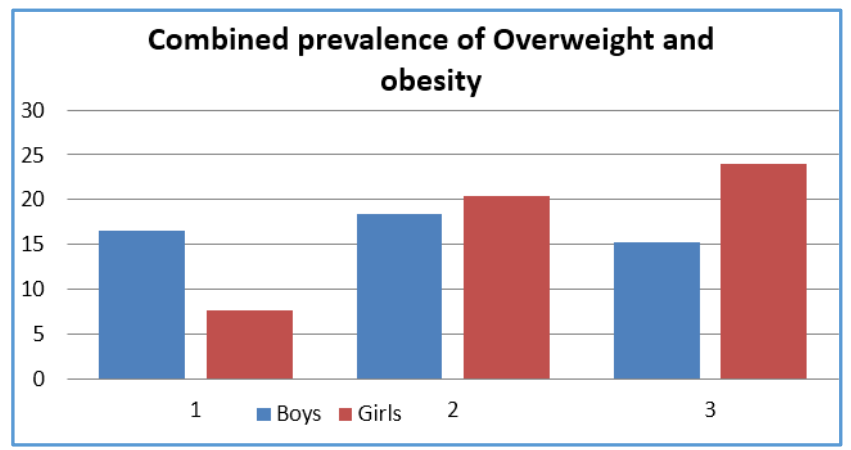

Figure 3

1. Age group- 7 years; 2 . Age group- 10 years; 3 . Age group13 years

\section{DISCUSSION}

This is a school-based study in which the students from class II (average age 7 years), V (average age 10 years) and VIII (average age 13 years) from urban schools and belonging to middle class families were included. Their general physical assessment was done and anthropometric measurements were taken.

Our study results show that though the undernutrition was noted in $9.53 \%$ study population using BMI as criteria and Revised IAP 2015 growth charts; the combined prevalence of overweight and obesity was $15.94 \%$.

By using Weight for age criteria, 8.05\% children were identified as overweight/obese and only 3.03 children were observed to be underweight.

Regardless of the parameter used, it was obvious that overweight and obesity is emerging as public health problem in children, especially amongst adolescents in urban part of
Pune. Similar findings have been reported in the study of age groups in studies conducted in different parts of India. $(9,10)$

Though different parameters and growth references were used to define overweight and obesity, higher prevalence of it has been reported from rural part of Maharashtra also.(11,12) The prevalence of overweight and obesity in young boys has been reported to be $19.9 \%$ and $5.7 \%$ respectively using International Obesity Task Force (IOTF) criteria in a study conducted in urban Pune.(13)

A relatively high prevalence of overweight and obesity has been observed in age group of 10 and 13 years, i.e. prepubertal and pubertal period. The proportion of overweight and obese children in our study increased with age. A study has shown similar results.(10)

The combined prevalence of overweight and obesity is higher in boys of classes II (Age about 7 years). This observation can be explained on the basis that boys are favoured over girls for access to calorie-dense food. This finding was similar to that seen in a study, where the prevalence was found to be more among boys as compared to girls. (14)

However, the prevalence of obesity in girls was more in adolescent girls. This may be associated with the increase in adipose tissue and overall weight gain during the puberty. The highest prevalence rate of overweight (28.5\%) and obesity (4.2\%) was observed in urban adolescent English medium school girls from Eastern part of India.(15)

Using BMI as criteria, more number of adolescents has been identified as having unhealthy nutritional status as compared to use of weight for age as criteria. Thus, BMI is very useful for early identification of both overweight/obese and undernourished children/adolescents. As per recommendation of the WHO expert group,(16) BMI and skinfold thickness (triceps and subscapular) should be used to evaluate obesity as well as thinness. As weight and height can be measured easily, BMI can be used as the parameter to identify children and adolescents at risk of overweight and obesity. $(17,18)$

BMI should be calculated in all settings where length/height measurements are possible and be plotted on Growth chart to assess current nutritional status. As per recommendations of American Academy of Paediatrics,(19) BMI should be calculated and plotted for all children to check for excess weight gain in children of all ages. BMI monitoring helps in early recognition of children at risk for overweight and obesity.

\section{CONCLUSION}

To conclude a significantly higher prevalence of overweight/obesity in children, especially among adolescents has been observed using BMI as a parameter. By plotting BMI of the children, even those at risk of undernutrition were picked in large number. Thus, BMI monitoring of all the children by paediatricians and other healthcare professionals can play a significant role in identifying the children at risk of unhealthy nutritional status among young children. Dual threat of undernutrition and overnutrition is still present even in urban school children. Therefore, there is a need to devise effective control measures, both home and school based and further research on risk factors for childhood unhealthy nutritional status. 


\section{Limitations}

The limitation of this study was school-based study and observations found cannot be used to assess the problem in community. The risk factors for undernutrition and overweight/obesity could not be studied, as this information was not specifically sought. However, strength of our study remains in the fact that it provides an overview of burden of childhood obesity and undernutrition among representative sample of children amongst the age groups of 7, 10 and 13. It was not possible to prove any causal relationship between overweight/obesity and its risk factors. Further studies will be needed to prove the same.

\section{Contributions}

The Authors had full access to all of the data in the study. Study concepts and design- DA, SP (Dept. of Paediatrics), Statistical Analysis- SR (Dept. of Community Medicine). All authors had equal contributions in writing this manuscript and all have read and approved the final manuscript.

\section{REFERENCES}

[1] Popkin BM. The nutrition transition and obesity in the developing world. J Nutr 2001;131(3):871S-3S.

[2] Kumaravel V, Shriram V, Anitharani M, et al. Are the current Indian growth charts really representative? Analysis of anthropometric assessment of school children in a South Indian district. Indian J Endocr Metab 2014;18(1):56-62.

[3] Tanner JM. Fetus into man. In: Tanner JM. edr. Physical growth from conception to maturity. $1^{\text {st }}$ edn. New York, Wells: Open Book Publishing Limited., 1978:2236.

[4] Roland-Cachera MF. Body composition during adolescence: methods, limitations and determinants. Horm Res 1993;39(Suppl 3):25-40.

[5] Zemel BS, Ritey EM, Stallings VA. Evaluation of methodology for nutritional assessment in children: anthropometry, body composition and energy expenditure. Ann Rev Nutr 1997;17:211-35.

[6] Garrow JS, Webster J. Quetelet's index $\left(\mathrm{W} / \mathrm{H}^{2}\right)$ as a measure of fatness. Int J Obes 1985;9(2):147-53.

[7] Higgins M, Kannel W, Garrison R, et al. Hazards of obesity-the Flamingham experience. Acta Med Scand Suppl 1988:723:23-36.
[8] Khadilkar VV, Yadav S, Agrawal KK, et al. Revised Indian Academy of Pediatrics 2015 growth charts for height, weight and body mass index for 5-18 years in Indian children. Indian Pediatr 2015;52(1):47-55.

[9] Cherian AT, Cherian SS, Subbiah S. Prevalence of obesity and overweight in urban school children in Kerala, India. Indian Pediatr 2012;49(6):475-7.

[10] Mahajan PB. Study of childhood obesity among school children aged 6 to 12 years in Union Territory of Puducherry. Ind J Community Medicine 2011;36(1):45-50.

[11] Jiwane N, Wadhwa S, Prevalence of overweight and obesity in rural school children of Maharashtra, India. Int J Sci Res 2014;3(5):405-6.

[12] Kawatra A, Trygg N, Parhar G, et al. Waist circumference and waist-height ratio percentiles for assessing childhood obesity: cross-sectional survey in rural Indian child population. Indian J Basic Appl Med Res 2013:3(1):246-56.

[13] Khadilkar VV, Khadilkar AV. Prevalence of obesity in affluent school boys in Pune. Indian Pediatr 2004;41:857-8.

[14] Kurlekar U, Oka G, Khare A. Prevalence of childhood overweight and obesity in rural Pune. Indian J Child Health 2016:3(4):301-4.

[15] Mandal A, Mandal GC. Prevalence of overweight and obesity among the urban adolescent english medium school girls of Kolkata, India. Italian J of Public Health 2012;9(3):e7535-16.

[16] Physical status: the use and interpretation of anthropometry-report of a WHO Expert Committee, Geneva. World Health Organization, 1995:263-308.

[17] Himes JH, Bouchard C, Validity of anthropometry in classing youths as obese. Intern $\mathrm{J}$ Obesity 1989;13:183-93.

[18] Malina RM, Katzmarzyk PT. Validity of body index as an indicator of the risk and presence of overweight in adolescents. Am J Clin Nutr 1999;70(1 Pt 2):131S-6S.

[19] American Academy of Pediatrics: Committee on Nutrition. Prevention of pediatric overweight and obesity. Pediatr 2007:119(2):405. 